\title{
Increased PADI4 expression in blood and tissues of patients with malignant tumors \\ Xiaotian Chang ${ }^{*}$, Jinxiang Han ${ }^{1}$, Li Pang ${ }^{2}$, Yan Zhao ${ }^{1}$, Yi Yang ${ }^{3}$ and Zhonglin Shen ${ }^{3}$
}

Address: ${ }^{1}$ Key Laboratory for Bio-drugs of Ministry of Health, Research Center For Medicinal Biotechnology, Shandong Academy of Medical Sciences, Jingshi Road 89, Jinan, Shandong, 250062, PR China, ${ }^{2}$ Shandong University 2nd Hospital, Shandong University Medical School, Jinan, Shandong, PR China and ${ }^{3}$ Yankuang Hospital of Yanzhou, Yanzhou, Shandong, PR China

Email: Xiaotian Chang* - changxt@126.com; Jinxiang Han - jinxiang.han@163.com; Li Pang - lipang2h@163.com;

Yan Zhao - zhaoyansdams@163.com; Yi Yang - yiyang@163.com; Zhonglin Shen - zhonglinshen@163.com

* Corresponding author

Published: 30 January 2009

BMC Cancer 2009, 9:40 doi:10.1 186/147|-2407-9-40
Received: 26 July 2008

Accepted: 30 January 2009

This article is available from: http://www.biomedcentral.com/I47I-2407/9/40

(C) 2009 Chang et al; licensee BioMed Central Ltd.

This is an Open Access article distributed under the terms of the Creative Commons Attribution License (http://creativecommons.org/licenses/by/2.0), which permits unrestricted use, distribution, and reproduction in any medium, provided the original work is properly cited.

\begin{abstract}
Background: Peptidylarginine deiminase type 4 (PAD4/PADI4) post-translationally converts peptidylarginine to citrulline. Recent studies suggest that PADI4 represses expression of $p 53$-regulated genes via citrullination of histones at gene promoters.

Methods: Expression of PADI4 was investigated in various tumors and non-tumor tissues $(n=1673)$ as well as in A549, SKOV3 and U937 tumor cell lines by immunohistochemistry, real-time PCR, and western blot. Levels of PADI4 and citrullinated antithrombin (CAT) were investigated in the blood of patients with various tumors by ELISA $(n=|I| 2 \mid)$.

Results: Immunohistochemistry detected significant PADI4 expression in various malignancies including breast carcinomas, lung adenocarcinomas, hepatocellular carcinomas, esophageal squamous cancer cells, colorectal adenocarcinomas, renal cancer cells, ovarian adenocarcinomas, endometrial carcinomas, uterine adenocarcinomas, bladder carcinomas, chondromas, as well as other metastatic carcinomas. However, PADI4 expression was not observed in benign leiomyomas of stomach, uterine myomas, endometrial hyperplasias, cervical polyps, teratomas, hydatidiform moles, trophoblastic cell hyperplasias, hyroid adenomas, hemangiomas, lymph hyperplasias, schwannomas, neurofibromas, lipomas, and cavernous hemangiomas of the liver. Additionally, PADI4 expression was not detected in non-tumor tissues including cholecystitis, cervicitis and synovitis of osteoarthritis, except in certain acutely inflamed tissues such as in gastritis and appendicitis. Quantitative PCR and western blot analysis showed higher PADI4 expression in gastric adenocarcinomas, lung adenocarcinomas, hepatocellular carcinomas, esophageal squamous cell cancers and breast cancers ( $n=5$ for each disease) than in the surrounding healthy tissues. Furthermore, western blot analysis detected PADI4 expression in cultured tumor cell lines. ELISA detected increased PADI4 and cAT levels in the blood of patients with various malignant tumors compared to those in patients with chronic inflammation and benign tumors. This was consistent with immunohistochemical results. Additionally, PADI4 and cAT levels were significantly associated with higher levels of known tumor markers.
\end{abstract}

Conclusion: Our results suggest that PADI4 expression is increased in the blood and tissues of many malignant tumors, a finding useful for further understanding of tumorigenesis. 


\section{Background}

In a process known as citrullination, peptidylarginine deiminase type 4 (PAD4/PADI4) post-translationally converts peptidylarginine to citrulline. Previously, Cuthbert et al. had found that citrullination by PADI4 prevents arginine methylation of histones $\mathrm{H} 3$ and $\mathrm{H} 4$ during transcriptional activation of estrogen-responsive genes [1]. Further evidence has confirmed that PADI4 is significantly associated with rheumatoid arthritis (RA), thus playing an important role in the pathogenesis of this disease [2]. We previously detected intense PADI4 expression in tumor cells from various adenocarcinomas, but not in healthy tissues [3]. We also demonstrated co-localization of PADI4 with cytokeratin, an intermediate filament protein that plays a role during cell differentiation and apoptosis [3-6]. To further confirm these findings, we investigated PADI4 expression by immunohistochemistry, real-time PCR and western blot analysis in various benign tumors and non-tumor inflamed tissues in the current study. Due to the relatively low, sometimes undetectable, expression of PADI4 in tumor tissue extracts, we performed western blot following immunoprecipitation in the study. We also examined PADI4 expression in cultured lung adenocarcinoma (A549), ovarian adenocarcinoma (SKOV3), and leukemia (U937) cell lines. Additionally, we investigated PADI4 levels in the blood of patients with various tumors in the present study. Since we previously detected citrullination and subsequent inactivation of antithrombin in the plasma of RA patients [7], we also measured levels of citrullinated antithrombin (cAT) in the blood of patients containing various tumor types. By analyzing levels of PADI4 and cAT, as well as the levels of known tumor markers, we aimed to explore the pathogenic role of PADI4 during carcinogenesis.

\section{Methods \\ Immunohistochemistry}

Various malignant tumors, benign tumors and non-tumor inflamed tissues $(n=1673$, see Table 1$)$ were collected during excision surgery at several hospitals in the Shandong region of China. Tumor diagnosis was verified by histological methods, and pathological categorization was determined according to the World Health Organization (WHO) classification system. All patients signed informed consents, and this study was approved by the ethics committee of Shandong Academy of Medical Sciences.

Tissue samples were fixed in 10\% neutral buffered formalin and embedded in paraffin. Tissue sections were deparaffinized and rehydrated using standard procedures. To increase the intensity of immunostaining, the sections were heated at $95^{\circ} \mathrm{C}$ for $10 \mathrm{~min}$ in citrate buffer $(0.01 \mathrm{M}$, $\mathrm{pH}$ 0.6), then incubated overnight at $4^{\circ} \mathrm{C}$ with antiPADI4 antibody. Anti-PADI4 was prepared by immuniz- ing rabbits with the synthetic oligopeptide FGDSCYPSNDSRQMH, and immunospecificity was confirmed in a previous study [3]. Immunoreactions were processed using the UltraSensitive TM S-P Kit (Maixin-Bio, China) according to the manufacturer's instructions, and signals were visualized using the DAB substrate, which stains the target protein yellow.

The intensity of immunosignals was evaluated by a previously described protocol from Denkert et al. [8]. For each histological section, the percentage of positive cells was scored as $0(0 \%), 1(10 \%), 2(10-50 \%), 3(51-80 \%)$ and $4(>80 \%)$, and the staining intensity was scored as 0 (negative), 1 (weak), 2 (moderate) and 3 (strong). The immunoreactive score (IRS) was obtained by multiplying the percentage of positive cells and the staining intensity. Immunohistochemical results with an IRS of $0-1$ were considered negative, $1-2$ weak and 6-12 positive.

\section{Immunoprecipitation and western blot analysis}

Gastric adenocarcinomas $(\mathrm{n}=5)$, lung adenocarcinomas $(n=5)$, hepatocellular carcinomas $(n=4)$, esophageal squamous cell cancers $(n=5)$, breast cancers $(n=5)$, and breast fibroadenomas $(n=5)$ were collected during excision surgery. Normal, healthy tissues located $5 \mathrm{~cm}$ away from the corresponding tumors were collected during surgery for control histological examinations. Sample tissues (200 ug) were homogenized with Cell Lysis Solution (Sigma) and centrifuged at $16000 \times \mathrm{g}$ for $5 \mathrm{~min}$ at $4^{\circ} \mathrm{C}$. The supernatant was collected, and protein concentrations were determined using the BCA Protein Assay Kit (Pierce). Immunoprecipitation (IP) was performed using a Protein G Immunoprecipitation Kit (Sigma) according to the manufacturer's instructions. Briefly, an equal amount of lysate from each sample was incubated overnight at $4^{\circ} \mathrm{C}$ with the PADI4 antibody in the presence of a Protease Inhibitor Cocktail (Sigma). Protein G beads were added to the mixture and incubated for $2 \mathrm{~h}$ at $4^{\circ} \mathrm{C}$. After thorough washing, the purified PADI4 protein was eluted with $1 \times$ Laemmli sample buffer (Sigma). IP samples $(10 \mathrm{ul})$ were separated by SDS-PAGE and then transferred onto PVDF membranes using the Mini-PROTEAN 3 system (Biorad). The membranes were probed with monoclonal anti-PADI4 antibody containing a recombinant fragment of human PADI4 between residues 2-111 (Abcam), and then incubated with sheep anti-mouse IgG conjugated to alkaline phosphatase (Sigma). Immunosignals were visualized with the Protein Detector BCIP/NBT Western Blot Kit (KPL) following the manufacturer's instructions.

We also measured PADI4 expression in total protein extracts from the tumor cell lines A549, SKOV3 and U937. Preparation of protein extracts was performed as described above. 
Table I: The PADI4 expression in tumors and non-tumor inflamed tissues

\begin{tabular}{|c|c|c|c|}
\hline tissues & expression & no expression & positivity $\%$ \\
\hline breast cancer & 144 & 6 & 96 \\
\hline breast fibroadenoma & 5 & 72 & 6.5 \\
\hline esophageal squamous cell cancer & 80 & 15 & 84.2 \\
\hline gastric adenocarcinoma & 56 & 10 & 84.8 \\
\hline rodents & 24 & 38 & 38.7 \\
\hline gastritis & 20 & 44 & 31.2 \\
\hline leiomyosarcoma of stomach & 7 & 38 & 15.6 \\
\hline colorectal adenocarcinoma & 24 & 4 & 85.7 \\
\hline cholecystitis & 0 & 20 & 0 \\
\hline appendicitis & 20 & 4 & 83.3 \\
\hline myoma of uterus & 0 & 60 & 0 \\
\hline endometrial hyperplasia of uterus & 10 & 66 & 13.1 \\
\hline endometrial carcinoma & 31 & 1 & 96.8 \\
\hline cervical polyp & 0 & 20 & 0 \\
\hline cervicitis & 0 & 20 & 0 \\
\hline hydatidiform mole & 0 & 20 & 0 \\
\hline ovarian carcinoma & 66 & 2 & 97 \\
\hline hydatidiform mole & 0 & 20 & 0 \\
\hline teratoma & 8 & 40 & 16.7 \\
\hline primary lymphoma & 20 & 8 & 71.4 \\
\hline lymphadenitis & 0 & 20 & 0 \\
\hline skin cancer & 20 & 0 & 100 \\
\hline intradermal nevus & 0 & 20 & 0 \\
\hline lipoma & 0 & 20 & 0 \\
\hline hepatocellular carcinoma & 20 & 0 & 100 \\
\hline hepatoblastoma & 0 & 20 & 0 \\
\hline liver cirrhosis & 108 & 52 & 67.5 \\
\hline hepatic cavernous hemangioma & 0 & 72 & 0 \\
\hline lung adenocarcinoma & 62 & 0 & 100 \\
\hline renal cell carcinoma & 47 & 7 & 87 \\
\hline chondroma & 20 & 0 & 100 \\
\hline osteosarcoma & 50 & I & 98 \\
\hline bladder carcinomas & 20 & 0 & 100 \\
\hline metastatic carcinoma & 20 & 0 & 100 \\
\hline thyroid adenoma & 0 & 40 & 0 \\
\hline hemangioma & 0 & 20 & 0 \\
\hline neurofibroma & 0 & 20 & 0 \\
\hline pleomorphic adenoma of salivary & 2 & 22 & 8.3 \\
\hline synovitis & 0 & 18 & 0 \\
\hline
\end{tabular}

\section{ELISA}

Blood samples were collected from patients with malignant tumors 4-6 days prior to and after tumor excision surgery. Blood from healthy volunteers and from patients with benign tumors or non-tumor inflammation were used as controls. All samples ( $\mathrm{n}=1121$, see Table 2$)$ were collected in Monovette tubes containing 3.8\% sodium citrate and centrifuged at $1500 \times \mathrm{g}$ for $20 \mathrm{~min}$. Supernatants of anticoagulated plasma were collected and stored at $80^{\circ} \mathrm{C}$ until use. Plasma samples were diluted 1:20 in 0.05 $\mathrm{M}$ carbonate-bicarbonate buffer ( $\mathrm{pH} 9.6)$ and used to coat 96-well EIA/RIA microplates (Costar) overnight at $4{ }^{\circ} \mathrm{C}$. After a brief wash with PBST ( $8 \mathrm{~g} \mathrm{NaCl}, 0.2 \mathrm{~g} \mathrm{KCl}, 1.15 \mathrm{~g}$ $\mathrm{NaHPO}_{4}$ and $0.2 \mathrm{~g} \mathrm{KH}_{2} \mathrm{PO}_{4}$ per liter, $\mathrm{pH}$ 7.4-7.6, $0.1 \%$ Tween 20), plates were blocked with $5 \%$ non-fat dry milk for $1 \mathrm{~h}$ at room temperature. Anti-PADI4 antibody (diluted 1:4000 in PBST) was added to the plates and incubated for $2 \mathrm{~h}$ at room temperature. After washing with PBST, plates were incubated with 1:10,000 anti-rabbit IgG conjugated to alkaline phosphatase (Sigma) for $30 \mathrm{~min}$ at room temperature. Plates were then washed with PBST, and the signal was developed by adding the Alkaline Phosphatase Yellow (pNpp) Liquid Substrate System for ELISA (Sigma). Absorbance at $405 \mathrm{~nm}$ was measured using a spectrophotometer (Synergy HT, Bio-Tek).

\section{Sandwich ELISA}

Anti-human antithrombin monoclonal antibody (Abcam) was diluted 1:5000 in $0.05 \mathrm{M}$ carbonate-bicarbonate buffer ( $\mathrm{pH}$ 9.6) and used to coat microplates overnight at $4{ }^{\circ} \mathrm{C}$. After a brief wash with PBST, the plates were blocked with $5 \%$ non-fat dry milk for $1 \mathrm{~h}$ at room temper- 
ature. Plasma samples diluted 1:20 in PBST were added to the plates and incubated for $2 \mathrm{~h}$ at room temperature. After washing with PBST, plates were incubated with 1:4000 rabbit anti-citrulline (Abcam) for $1 \mathrm{~h}$ at room temperature. The anti-citrulline antibody was labeled with alkaline phosphatase using the AP Labeling Kit (Roche) according to the manufacturer's instructions. The plates were then washed with PBST, and signals were detected as described above.

\section{Measure of tumor markers in patient blood samples}

CEA levels were measured in all blood samples, AFP levels in liver cancer samples, CA199 levels in digestive tract tumor samples, CA125 levels in ovarian cancer samples, CA153 levels in breast cancer samples, CYFRA21-1 levels in lung cancer samples, and PSA levels in prostate cancer samples. All measurements were performed in a clinical laboratory cooperating with us.

ELISA data were collected from three independent tests. All statistical analyses were conducted using SPSS (version 11.0). The median and range of PADI4 and CAT levels are reported. The Mann-Whitney U-test statistically assessed differences between the groups, and the $\mathrm{x}^{2}$ test was used to examine the association between expression of PADI4, cAT and several tumor markers. P values $\leq 0.05$ were considered as statistically significant.

\section{Real-Time Quantitative PCR}

Total RNA was extracted using the TRIzol reagent (Invitrogen) from gastric adenocarcinomas $(n=5)$, lung adenocarcinomas $(n=5)$, hepatocellular carcinomas $(n=4)$, esophageal squamous cell cancers $(n=5)$, breast cancers $(n=5)$ and breast fibroadenomas $(n=5)$, as well as their corresponding healthy tissues. Concentrations of total RNA were determined with a spectrophotometer. Quantitative PCR analyses were performed using the iCycler Real-Time Detection System (Bio-Rad). Gene-specific primers were designed using the PADI4 mRNA sequence in Genbank (NM012387) and were as follows: forward 5'ctgtggtgttccaagacagc-3' (nt position 871-890) and reverse 5'-gcttggatgtagccgatctc-3' (nt position 1083-1102). The TaqMan probe 5'-cccaacacccagccccogca-3' (nt position 924-943) was labeled at the 5' end with the reporter dye FAM (6-carboxy-fluorescein) and at the 3 ' end with the quencher TAMRA (6-carboxy-teremethyl-rhodamine) (TaKaRa). cDNA was prepared with 1 ug of total RNA from each sample using random hexamers and reverse transcription with the PrimeScriptTM RT-PCR Kit (TaKaRa). A 232 bp DNA fragment was produced by 1st strand cDNA synthesis with the above primer set, cloned into the pGEM-T Easy Vector (Promega), and verified by sequence analysis. Purified recombinant plasmid was serially diluted to $1 \times 10^{7}, 1 \times 10^{6}, 1 \times 10^{5}, 1 \times 10^{4}, 1 \times 10^{3}$ and $1 \times 10^{2}$ copies $/ \mathrm{ml}$. TaqMan real-time PCR was performed using the PrimeScriptTM RT-PCR Kit (TaKaRa) in $25 \mathrm{ul}$ of reaction mixtures containing 12.5 ul of Premix Ex Taq, 0.5 $\mathrm{ul}$ of forward primer $(10 \mathrm{uM}), 0.5 \mathrm{ul}$ of reverse primer (10 $\mathrm{uM}), 1 \mathrm{ul}$ of TaqMan probe ( $3 \mathrm{uM}), 2 \mathrm{ul}$ of recombinant plasmid or cDNA and $8.5 \mathrm{ul}$ of $\mathrm{H}_{2} \mathrm{O}$. The following optimized thermal cycling program was used: denaturation at $95^{\circ} \mathrm{C}$ for $3 \mathrm{~min}$, followed by 50 cycles of $95^{\circ} \mathrm{C}$ for $30 \mathrm{~s}$ and $60^{\circ} \mathrm{C}$ for $30 \mathrm{~s}$; fluorescence data were collected at the $60^{\circ} \mathrm{C}$ annealing and extension step. The PCR threshold cycle (Ct), which is defined as the fractional cycle number at which the fluorescence reaches 10 times the standard deviation of the baseline, was determined by the iCycler iQ software. Standard curve equations were calculated by regression analysis of the average $\mathrm{Ct}$ versus the $\log 10$ of the standard copy number. Copy numbers of PADI4 mRNA in clinical samples were calculated automatically by the data analysis software.

\section{Results}

PADI4 expression was detected by immunohistochemistry in all malignant tumor types examined including breast carcinomas, lung adenocarcinomas, hepatocellular carcinomas, esophageal squamous cancer cells, colorectal adenocarcinomas, renal cancer cells, ovarian adenocarcinomas, endometrial carcinomas, uterine adenocarcinomas, bladder carcinomas, chondromas, and other metastatic carcinomas (IRS $\geq 9$ ). Furthermore, PADI4 was also expressed in over $40 \%$ of cells in malignant lymphomas (IRS $\geq 8$ ). In contrast, no significant levels of PADI4 were detected in various benign tumors including leiomyomas of the stomach, uterine myomas, endometrial hyperplasias, cervical polyps, teratomas, hydatidiform moles, trophoblastic cell hyperplasias, hyroid adenomas, hemangiomas, lymph hyperplasias, schwannomas, neurofibromas, lipomas, and cavernous hemangiomas of the liver (IRS: 0-1). In breast fibroadenoma, thyroid adenoma, and pleomorphic adenoma samples, PADI4 was observed in the endothelial cells of capillaries and gland structures (IRS: 1-6), both of which mainly consist of benign tissues. PADI4 expression was not detected in most non-tumor inflamed tissues including cholecystitis, cervicitis and synovitis of osteoarthritis (IRS $\leq 1$ ), although half of gastric ulcer and acute appendicitis samples displayed smeared PADI4 immunosignals (IRS: 3-6). In addition, more than $60 \%$ of the liver cirrhosis samples showed PADI4 expression (IRS: $3-8$ ). PADI4 was also expressed in several mesenchymal cells in both tumor and non-tumor inflamed tissues. Immunohistochemical results are shown and listed in Figure 1 and Table 1, respectively.

By western blot analysis, a $67 \mathrm{kDa}$ band was detected in IP extracts of gastric adenocarcinomas, lung adenocarcinomas, hepatocellular carcinomas, esophageal squamous cell cancers and breast cancers as well as in their corre- 

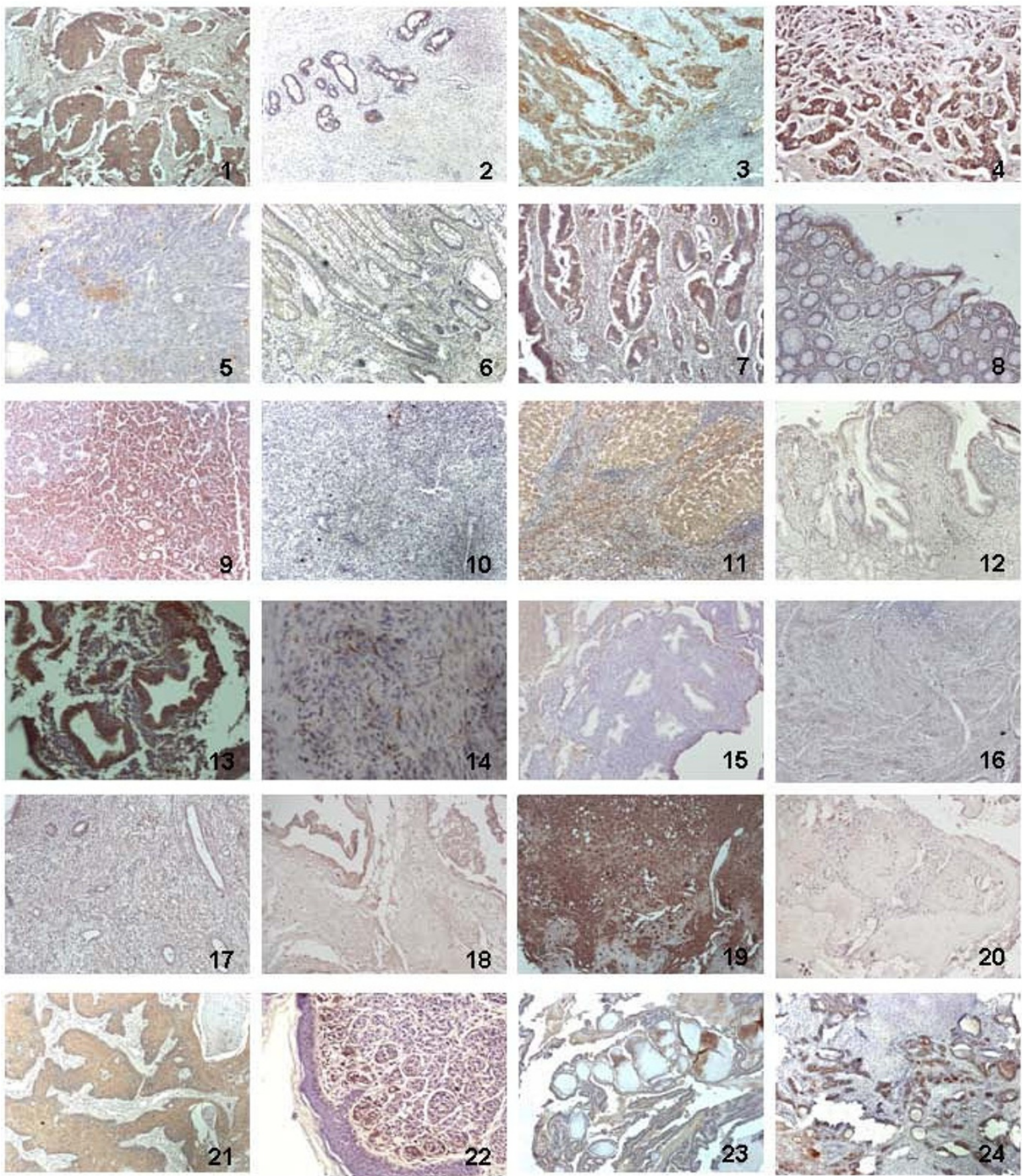

Figure I

Immunohistochemistry showing PADI4 expression in various malignant tumors, benign tumors and nontumor inflamed tissues. I. breast cancer, 2. breast fibroadenoma. 3. esophageal squamous cell cancer, 4. gastric adenocarcinoma, 5. leiomyosarcoma of stomach, 6. gastritis, 7. colorectal adenocarcinoma, 8. colorectal polyps, 9. hepatocellular carcinoma, I0. hepatoblastoma, II. liver cirrhosis, 12. cholecystitis, 13. endometrial carcinoma, 14. myoma of uterus, I5. endometrial hyperplasia of uterus, 16. cervicitis, 17. cervical polyp, 18. hydatidiform mole, 19. chondroma, 20. teratoma, 21. skin cancer, 22. intradermal nevus, 23. thyroid adenoma, 24. pleomorphic adenoma of salivary gland. The tissue structure of the section was defined by counterstaining with hematoxylin. The brown color in nevus cells was caused by pigment sediment. The color was also observable in the control sections without treatment of Ist or 2 nd antibody. Original magnification was 100x. 
sponding healthy tissues (see Figure 2). Immunosignal densities were significantly higher in malignant tissues than in corresponding healthy tissues or in breast fibroadenomas. Since IP extracts were purified from equivalent tissue weights for each sample, the density of the immunosignals directly corresponded to PADI4 expression levels. In addition, PADI4 was detected in total protein extracts from A549, SKOV3 and U937 tumor cell lines.

TaqMan quantitative PCR was used to measure PADI4 transcription in tumor samples. Levels of PADI4 mRNA were determined from standard curves and amplification plots (based on the $\mathrm{Ct}$ and copy number). As cDNA templates were synthesized from an equivalent amount of total RNA for each sample, the copy number/ug total RNA directly corresponds to PADI4 expression levels in the tissue samples. PADI4 transcripts were detected in gastric adenocarcinomas, lung adenocarcinomas, hepatocellular carcinomas, esophageal squamous cell cancers, breast cancers and breast fibroadenomas as well as their corresponding healthy tissues. PADI4 mRNA levels were significantly elevated in malignant tissues compared to those in corresponding healthy tissues. The PADI4 mRNA level in breast fibroadenomas was lower than that in breast cancers, but higher than that in corresponding healthy tissues. TaqMan quantitative PCR results are shown in Figure 3.

Plasma PADI4 levels of patients with malignant tumors were measured by ELISA and compared with those with benign and healthy controls. PADI4 levels were significantly increased in the blood of patients with breast carcinomas, hepatocellular carcinomas, lung cancer, esophageal carcinomas, gastric cancer, colon cancer, rectal cancer, pancreatic cancer, ovarian carcinomas, renal cell carcinomas, cervical cancer, prostate carcinomas and bladder carcinomas ( $\mathrm{p}<0.01$ ), but not in those with endometrial carcinomas, uterine myomas and thyroid carcinomas. After tumor excision surgery, PADI4 levels in the blood decreased considerably in breast carcinomas, hepatocellular carcinomas, lung cancer, gastric cancer, colon cancer, rectal cancer and pancreatic cancer samples ( $\mathrm{p}<0.05$ ). Meanwhile, plasma PADI4 levels in patients with chronic gastritis, chronic nephritis and cervicitis did not considerably change, or even declined, compared to samples from healthy control patients. However, patients with breast fibroadenomas, thyroid adenomas, hepatitis A and $\mathrm{B}$, liver cirrhosis, pulmonitis, acute pancreatitis and acute appendicitis had higher plasma PADI4 levels than those of healthy controls, with some samples showing even higher levels than that observed for patients with malignancies. ELISA results of PADI4 are shown in Figure 4.

Plasma cAT levels of patients with malignant tumors were measured by sandwich ELISA and compared to those with benign tumors and healthy controls. Plasma cAT levels were significantly elevated in most patients with malignant tumors, including those with breast carcinomas, hepatocellular carcinomas, lung carcinomas, esophageal carcinomas, gastric cancer, colon cancer, rectal cancer, pancreatic cancer, ovarian carcinomas, bladder carcinomas, uterine myomas, thyroid carcinomas and prostate carcinomas ( $\mathrm{p}<0.01)$, but not in those with cervical cancer or endometrial carcinomas. After tumor excision surgery, cAT levels in the blood declined for most

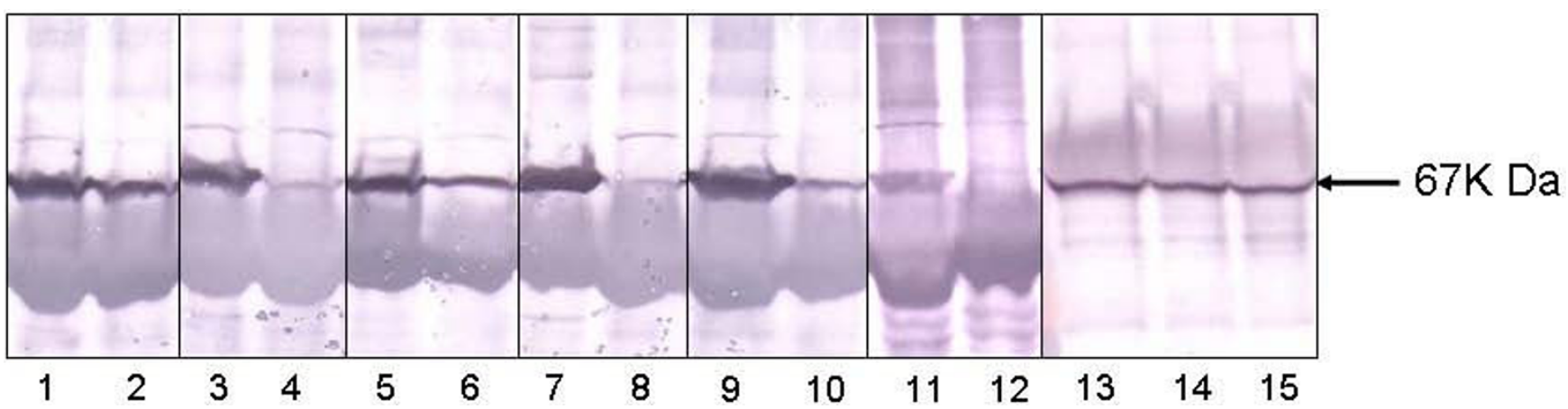

Figure 2

Western blot analysis of PADI4 expression in tumor cell lines, tumors and corresponding healthy tissues. Extracts were fractioned by electrophoresis and probed with anti-PADI4 antibody. PADI4 immunosignals (67 kDa) were detected in malignant tissues, tumor cell lines and some healthy tissues. Densities of the signals were significantly stronger in tumor tissues than in the corresponding healthy controls. Lanes I-2, gastric adenocarcinomas and corresponding healthy tissues; lanes 3-4 lung adenocarcinomas and corresponding healthy tissues; lanes 5-6, hepatocellular carcinomas and corresponding healthy tissues; lanes 7-8, esophageal squamous cell cancers and corresponding healthy tissues; lanes 9-10, breast cancers and corresponding healthy tissues; lanes II-I2, breast fibroadenomas and corresponding healthy tissues; and lanes I3-I5, A549, SKOV3 and U937 cells, respectively. 


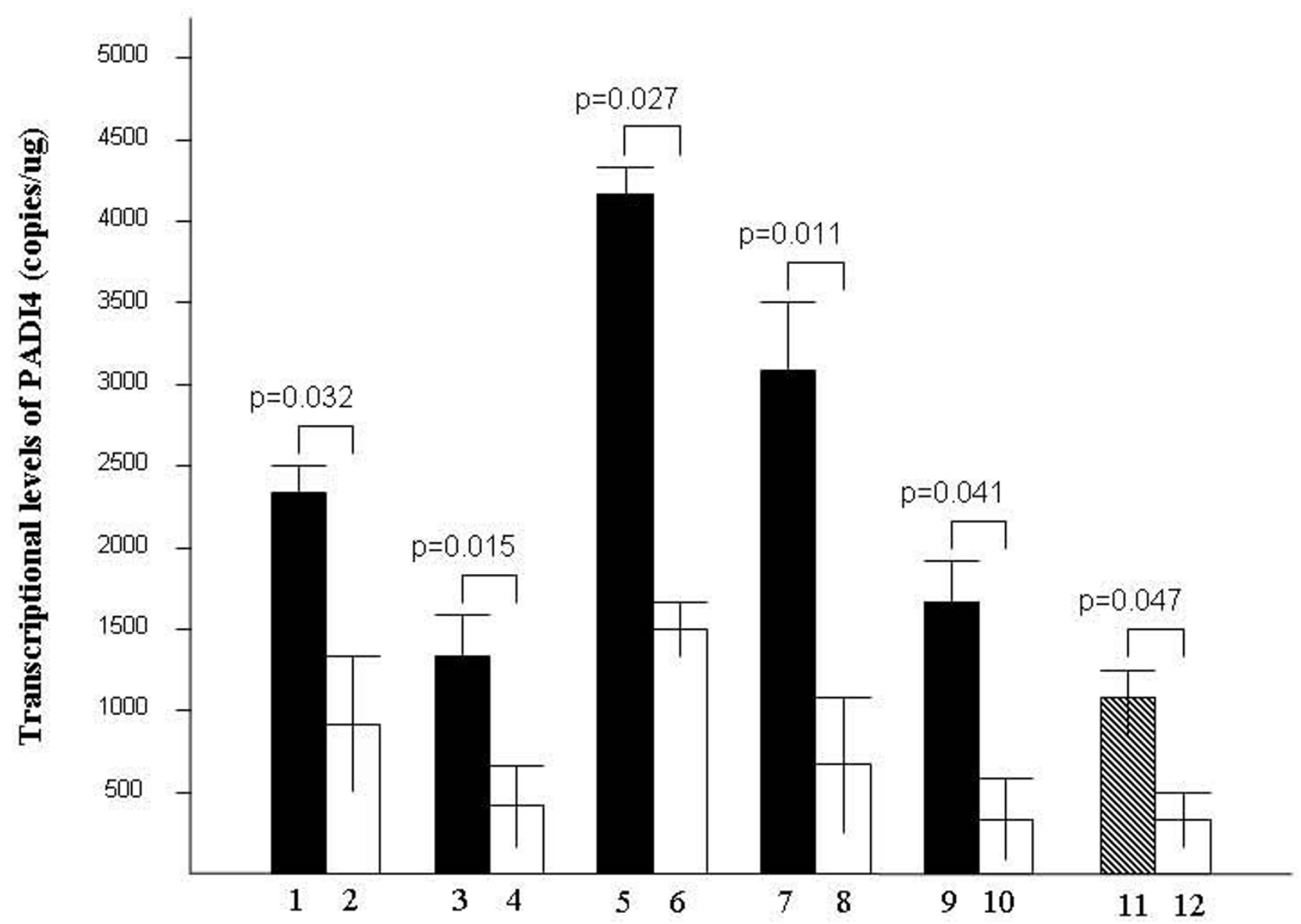

Figure 3

PADI4 transcription levels in tumors and corresponding healthy tissues by TaqMan quantitative PCR. CDNA templates were synthesized using an equivalent amount of total RNA for each sample. Lanes I-2, PADI4 mRNA levels in gastric adenocarcinomas and corresponding healthy tissues; lanes 3-4, lung adenocarcinomas and corresponding healthy tissues; lanes 5-6, hepatocellular carcinomas and corresponding healthy tissues; lanes 7-8, esophageal squamous cancer cells and corresponding healthy tissues; lanes 9-10, breast cancer cells and corresponding healthy tissues; and lanes II-I2, breast fibroadenomas and corresponding healthy tissues.

malignancies. Plasma cAT expression was not considerably altered in patients with breast fibroadenomas, acute pancreatitis, chronic nephritis and cervicitis, and displayed slightly diminished levels in patients with chronic gastritis and acute appendicitis when compared to those of healthy control subjects. The cAT content was higher in samples from patients with thyroid adenomas, hepatitis A and $\mathrm{B}$, liver cirrhosis and pulmonitis compared to healthy controls (see Figure 4). cAT levels associated significantly with PADI4 levels in patients with hepatocellular carcinomas, lung cancer, ovarian cancer, endometrial carcinomas and thyroid adenomas $(\mathrm{p}<0.01)$. In addition, cAT levels clearly associated with CEA levels in the blood of patients with breast carcinomas $(\mathrm{p}=0.032)$, CA199 levels in those with gastric cancer $(\mathrm{p}=0.025)$, CEA levels in those with pancreatic cancer $(\mathrm{p}=0.05)$, CA125 levels in those with ovarian cancer $(\mathrm{p}=0.03)$, CEA levels in those with bladder cancer $(p=0.016)$, CEA in those with renal cell carcinomas $(\mathrm{p}=0.046)$, and PSA in those with prostate cancer $(\mathrm{p}=0.028)$. PADI4 levels also significantly associated with CEA levels in patients with gastric cancer $(p=0.05)$ and prostate cancer $(\mathrm{p}=0.028)$.

\section{Discussion}

We previously detected intense PADI4 expression in a variety of adenocarcinomas, but expression was absent in normal, healthy tissues [3]. In the current study, we demonstrated the presence of extensive PADI4 expression in malignant tissues, but not in most benign and non-tumor tissues. Furthermore, quantitative PCR and western blot 


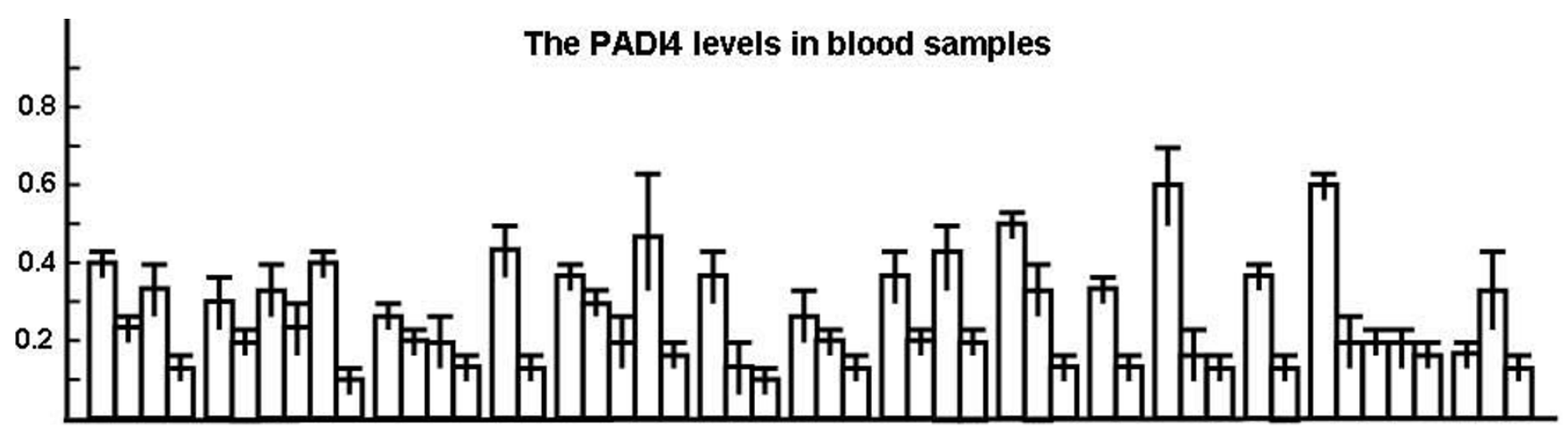

$1234456 \quad 78910111213141516171819202122232425262728293031323334353637383940414243444546474849$

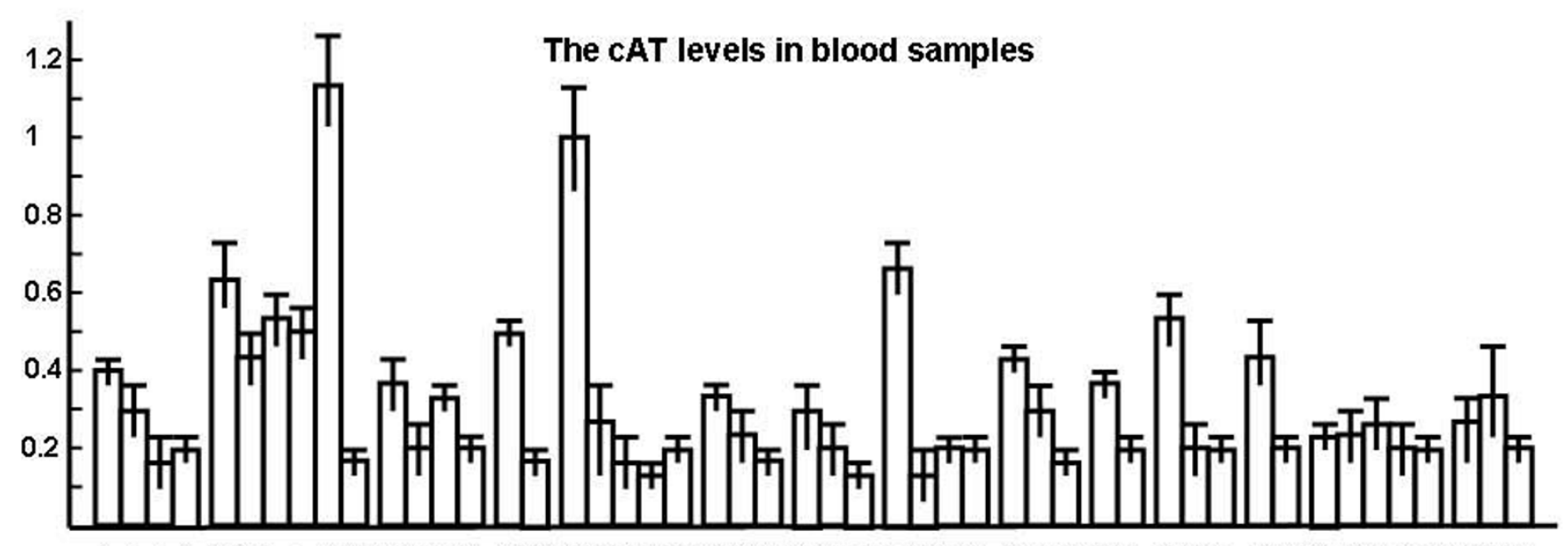

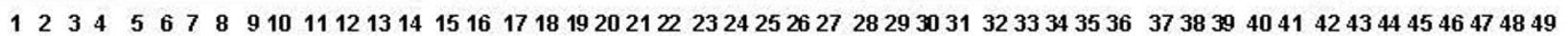

\section{Figure 4}

Levels of PADI4 and CAT in plasma of patients with various tumors. Plasma samples are listed as the followings: lane $I-4$ breast carcinoma $(n=112)$, after receiving surgery $(n=86)$, breast fibroadenomas controls $(n=30)$, and health controls $(n=42)$; 5-10 hepatocellular carcinomas $(n=77)$, after receiving surgery $(n=24)$, hepatitis $A$ controls $(n=28)$, hepatitis $B$ controls $(n=14)$, liver cirrhosis controls $(n=27)$, and healthy controls $(n=42)$; II-14 lung cancer $(n=127)$, after receiving surgery $(n=24)$, pulmonitis controls $(n=48)$, and healthy controls $(n=31) ; 15,16$ esophageal carcinomas $(n=64)$ and healthy controls $(n=44)$; I7-2I gastric cancer $(n=94)$, after receiving surgery $(n=43)$, chronic gastritis controls $(n=3 \mid)$, acute appendicitis controls $(n=22)$, and healthy controls $(n=38) ; 22-24$ colon cancer $(n=21)$, after receiving surgery $(n=15)$, and healthy controls $(n=17) ; 25-27$ rectal cancer $(n=19)$, after receiving surgery $(n=28)$, and healthy controls $(n=17)$; $28-31$ pancreatic cancer $(n=21)$, after receiving surgery $(n=6)$, acute pancreatitis controls $(n=7)$, and healthy controls $(n=60)$; 32-34 ovarian carcinomas $(n=29)$, after receiving surgery $(n=11)$, and healthy controls $(n=23) ; 35,36$ prostate cancer $(n=$ $18)$ and healthy controls $(n=23)$; 37-39 renal cell carcinomas $(n=19)$, chronic nephritis controls $(n=11)$, and healthy controls $(n=60) ; 40,4 I$ bladder carcinomas $(n=10)$ and healthy controls $(n=23) ; 42-46$ cervical cancer $(n=24)$, endometrial carcinomas $(n=15)$, uterine myomas $(n=34)$, cervicitis $(n=15)$, and healthy controls $(n=34) ; 47-49$ thyroid carcinomas $(n=$ $7)$, thyroid adenomas $(n=16)$, and healthy controls $(n=36)$.

analysis revealed significantly higher PADI4 mRNA and protein levels in malignant tissues compared to surrounding healthy tissues, which were consistent with immunohistochemical results. These findings indicated that PADI4 expression was increased in malignancies at both the transcriptional and translational levels. Additionally, PADI4 expression was detected by western blot in cultured A549, SKOV3 and U937 cancer cell lines. PADI4 expression was also detected by Abcam in cultured tumor cells such as HeLa, Jurkat, A431, HEK293, and HepG2 cells http://www.abcam.com/index.html?datash eet $=38772$. These results further confirmed PADI4 expression in various tumor types.

Here, relatively high PADI4 expression was observed in breast fibroadenomas and thyroid adenomas by immu- 
nohistochemistry. Co-localized PADI4 and CD34 expression in tumors, bone marrow as well as other healthy tissues suggested that cells expressing PADI4 may have originated from CD34+ stem cells [3]. As many adenomas contain more CD34+ cells [9-11], we accordingly observed extensive expression of the PADI4 enzyme in these tissues. Smeared expression of PADI4 was also detected in some non-tumor inflamed tissues such as rodents, acute gastritis and acute appendicitis. As neutrophils, monocytes, and macrophages are all derived from CD34+ stem cells and infiltrate injured tissues during inflammation [12], we expected and were able to detect PADI4 expression in these inflamed tissues. However, we note that the enzyme was predominantly located in tumor cells of malignant tissues.

Compared with healthy control subjects, high PADI4 levels were detected in the blood of patients with malignant tumors, which was consistent with results obtained by immunohistochemistry. Plasma PADI4 levels in patients with malignancies were considerably diminished after tumor excision surgery, suggesting that PADI4 protein circulates in the blood from corresponding tumor tissues. High PADI4 content was observed in breast fibroadenoma and thyroid adenoma samples, consistent with immunohistochemical results of adenomas. Although increased PADI4 levels in the blood were demonstrated in patients with acute pancreatitis and appendicitis, most patients with non-tumor inflammations, such as chronic gastritis, chronic nephritis, and cervicitis, did not exhibit variations in PADI4 levels, suggesting that PADI4 may be elevated in the blood under conditions of acute but not chronic inflammation.

High levels of cAT were detected in blood of patients with malignant tumors. Compared with PADI4 expression in the malignant tumors, cAT expression appeared to be more specific to malignant tumors and significantly associated with known tumor markers. Antithrombin is a primary plasma inhibitor of thrombin. By in vitro incubation, we previously demonstrated that a recombinant human PADI4 protein can inactivate the thrombin-inhibitory activity of human antithrombin III through citrullination [7]. Because the cAT content in the plasma declined after tumor excision surgery and was generally associated with PADI4 levels in the blood, we propose that the high cAT levels observed in the blood was due to citrullination of PADI4 in tumor tissues. Suppressed antithrombin III activity and unregulated thrombin activity have broadly been reported in the plasma of patients with lung adenocarcinomas, renal cell carcinomas, breast cancer, malignant melanomas, colon cancer, pancreatic adenocarcinomas, and larynx squamous cell carcinomas [13-16]. Thrombin activity can promote angiogenesis by increasing transcription of the VEGF receptor as well as metastasis and hyperplasia by inducing expression of integrin $\beta 3$ [17-19]. In the present study, high cAT production was specifically and primarily detected in blood of most malignant tumor types, but not in blood of benign tumors or non-tumor diseases, suggesting that citrullination of antithrombin may be involved in promoting carcinogenesis. Therefore, it is formally possible that deregulated thrombin activity drives thrombin-related tumorigenesis, including malignant proliferation, invasion and metastasis of tumor cells, as well as abnormal angiogenesis and fibrin deposition in tumor tissues.

Many studies have demonstrated the effects of hormone metabolism on tumorigenesis [20-24]. Using cultured MCF-7 cells originated from breast cancer, Dong et al. found that estrogen enhanced PADI4 transcription in an estrogen receptor-mediated manner [25]. Recently, both Yao et al. and Li et al. reported that PADI4 repressed expressions of p53 target genes, including OKL38, p21, CIP1 and WAF1, by modifying methylated arginine sites on histones $\mathrm{H} 3$ and $\mathrm{H} 4[26,27]$. These modifications consequently interrupt apoptosis and cell cycle progression, which are primary features of tumorigenic cells. Thus, these studies suggest that PADI4 plays a role during tumorigenesis by antagonizing regulation of p53 to tumor suppressor genes. However, we detected PADI4 primarily in the cytoplasm of tumor cells in most malignant tissues as well as citrullinated cytokeratin in certain malignant tumors [3]. As keratins (notably K5, K7, K8/K18, K19, and K20) exhibit characteristic expression patterns in human tumors, and have great importance in immunohistochemical tumor diagnosis of carcinomas $[6,28,29]$, it is thus possible that citrullination of histones, keratin and antithrombin are all involved in the tumorigenic process. Our proposed mechanism for PADI4 in tumorigenesis is shown in Figure 5.

\section{Conclusion}

Compared to benign and non-tumor diseases, many malignant tumor types exhibited increased PADI4 expression in tumorous cells. Patients with malignant tumors also displayed higher plasma levels of both PADI4 and cAT than patients with benign and non-tumor inflammations. Plasma levels of cAT and PADI4 in patients with these malignancies were significantly associated with levels of known tumor markers. Our results implicate the importance of PADI4 and citrullination in the promotion of tumorigenesis. However, further study is needed to understand the exact pathogenic mechanism.

\section{Competing interests}

The authors declare that they have no competing interests. 


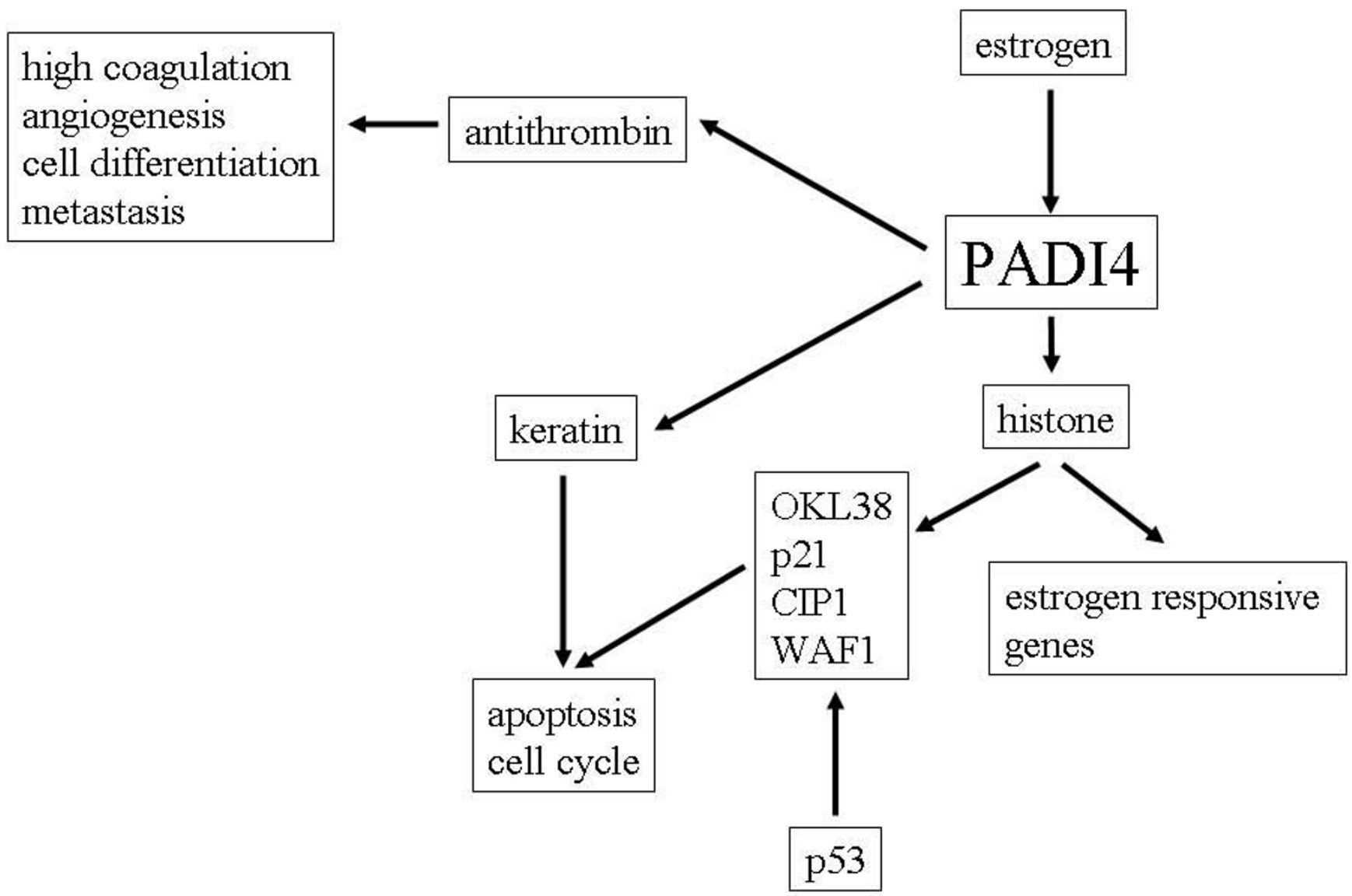

Figure 5

Proposed mechanism of PADI4 for tumorigenesis.

\section{Authors' contributions}

X.C. designed the study, performed experiments and prepared the manuscript; J.H. evaluated data; Y.Z. performed experiments; L.P., Y.Y. and Z.S. collected tissue and blood samples.

\section{Acknowledgements}

The present study was supported by the National Natural Science Foundation of China (30671949), the Science Promotion Foundation of Shandong (2006GG2202050, 2007GG2000200I), the Shandong Scientific Instrument Equipment Promotion Transformation Project (2006GGI I08097-4I, 2007GG2TC02050), and the Foundation for Scientific and Technological Achievements of Jinan (2007/5034).

\section{References}

I. Cuthbert GL, Daujat S, Snowden AW, Erdjument-Bromage H, Hagiwara T, Yamada M, Schneider R, Gregory PD, Tempst P, Bannister AJ, Kouzarides T: Histone deimination antagonizes arginine methylation. Cell 2004, I I 8:545-553.

2. Suzuki A, Yamada R, Chang X, Tokuhiro S, Sawada T, Suzuki M, Nagasaki M, Nakayama-Hamada M, Kawaida R, Ono M, Ohtsuki M, Furukawa H, Yoshino S, Yukioka M, Tohma S, Matsubara T, Wakitani S, Teshima R, Nishioka Y, Sekine A, lida A, Takahashi A, Tsunoda T, Nakamura Y, Yamamoto K: Functional haplotypes of PADI4, encoding citrullinating enzyme peptidylarginine deiminase
4, are associated with rheumatoid arthritis. Nat Genet 2003, 34:395-402.

3. Chang $X$, Han J: Expression of peptidylarginine deiminase type 4 (PAD4) in various tumors. Mol Carcinog 2006, 45: 183-196.

4. Oshima RG: Apoptosis and keratin intermediate filaments. Cell Death Differ 2002, 9:486-492.

5. Iwaya K, Mukai K: Accumulation of ubiquitin-conjugated cytokeratin fragments in tumor cells. Semin Cancer Biol 2005, I5:309-318.

6. Moll R, Divo M, Langbein L: The human keratins: biology and pathology. Histochem Cell Biol 2008, I 29:705-733.

7. Chang X, Yamada R, Sawada T, Suzuki A, Kochi Y, Yamamoto K: The inhibition of antithrombin by peptidylarginine deiminase 4 may contribute to pathogenesis of rheumatoid arthritis. Rheumatology (Oxford) 2005, 44:293-298.

8. Denkert C, Koch I, von Keyserlingk N, Noske A, Niesporek S, Dietel M, Weichert W: Expression of the ELAV-like protein HuR in human colon cancer: association with tumor stage and cyclooxygenase-2. Mod Pathol 2006, 19:|26|-|269.

9. Hristov M, Weber C: Endothelial progenitor cells: characterization, pathophysiology, and possible clinical relevance. J Cell Mol Med 2004, 8:498-508.

10. Moore T, Lee AH: Expression of CD34 and bcl-2 in phyllodes tumours, fibroadenomas and spindle cell lesions of the breast. Histopathology 2001, 38:62-67.

II. Rzeszutko M, Rzeszutko W, Dziegiel P: The morphological analysis of vasculature in thyroid tumours: immunoexpression of CD34 antigen. Folia Histochem Cytobiol 2004, 42:235-240.

12. Sherwood ER, Toliver-Kinsky T: Mechanisms of the inflammatory response. Best Pract Res Clin Anaesthesiol 2004, I 8:385-405. 
13. Ozyilkan O, Baltali E, Ozdemir O, Tekuzman G, Kirazli S, Firat D: Haemostatic changes; plasma levels of alpha2-antiplasminplasmin complex a thrombin-antithrombin III complex in female breast cancer. Tumori 1998, 84:364-367.

14. Wojtukiewicz MZ, Zacharski LR, Memoli VA, Kisiel W, Kudryk BJ, Rousseau SM, Stump DC: Fibrinogen-fibrin transformation in situ in renal cell Carcinoma. Anticancer Res 1990, 10:579-582.

15. Nakstad B, Lyberg T: Immunohistochemical localization of coagulation, fibrinolytic and antifibrinolytic markers in adenocarcinoma of the lung. APMIS I99I, 99:98I-988.

16. Bardos H, Juhasz A, Repassy G, Adany R: Fibrin deposition in squamous cell carcinomas of the larynx and hypopharynx. Thromb Haemost 1998, 80:767-772.

17. Maragoudakis ME, Tsopanoglou NE, Andriopoulou P: Mechanism of thrombin-induced angiogenesis. Biochem Soc Trans 2002, 30:173-177.

18. Wojtukiewicz MZ, Tang DG, Ciarelli JJ, Nelson KK, Walz DA, Diglio CA, Mammen EF, Honn KV: Thrombin increases the metastatic potential of tumor cells. Int J Cancer 1993, 54:793-806.

19. Sampson MT, Kakkar AK: Coagulation proteases and human cancer. Biochem Soc Trans 2002, 30:201-207.

20. Bulun SE, Simpson ER: Aromatase expression in women's cancers. Adv Exp Med Biol 2008, 630: I I 2-132.

21. Hammoud Z, Tan B, Badve S, Bigsby RM: Estrogen promotes tumor progression in a genetically defined mouse model of lung adenocarcinoma. Endocr Relat Cancer 2008, 15:475-483.

22. Krasner C: Aromatase inhibitors in gynecologic cancers. J Steroid Biochem Mol Biol 2007, 106:76-80.

23. Di Maio M, Daniele B, Pignata S, Gallo C, De Maio E, Morabito A, Piccirillo MC, Perrone F: Is human hepatocellular carcinoma a hormone-responsive tumor? World / Gastroenterol 2008, 14:1682-1689.

24. Slattery ML, Sweeney C, Murtaugh M, Ma KN, Wolff RK, Potter JD, Caan BJ, Samowitz W: Associations between ER alpha, ER beta, and $A R$ genotypes and colon and rectal cancer. Cancer Epidemiol Biomarkers Prev 2005, 14:2936-2942.

25. Dong S, Zhang Z, Takahara H: Estrogen-enhanced peptidylarginine deiminase type IV gene (PADI4) expression in MCF-7 cells is mediated by estrogen receptor-alpha-promoted transfactors activator protein-I, nuclear factor-Y, and Sp I. Mol Endocrinol 2007, 21:1617-1629.

26. Yao H, Li P, Venters BJ, Zheng S, Thompson PR, Pugh BF, Wang Y: Histone Argmodifications and p53 regulate the expression of OKL38, a mediator of apoptosis. J Biol Chem 2008, 283(29):20060-20068.

27. Li P, Yao H, Zhang Z, Li M, Luo Y, Thompson PR, Gilmour DS, Wang $Y$ : Regulation of p53 target gene expression by peptidylarginine deiminase. Mol Cell Biol 2008, 28:4745-4758.

28. Beham M, Ratschek K, Zatloukal C, Schmid H, Denk : Distribution of cytokeratins, vimentin and desmoplakins in normal renal tissue, renal cell carcinomas and oncocytoma as revealed by immunofluorescence microscopy. Virchows Arch A Pathol Anat Histopathol 1992, 421:209-215.

29. Schroder A, Wodzynski B, Padberg : Cytokeratin expression of benign and malignant epithelial thyroid gland tumors. An immunohistologic study of 154 neoplasms using 8 different monoclonal cytokeratin antibodies. Pathologe 1996, 17:425-432.

\section{Pre-publication history}

The pre-publication history for this paper can be accessed here:

http://www.biomedcentral.com/1471-2407/9/40/prepub
Publish with Biomed Central and every scientist can read your work free of charge

"BioMed Central will be the most significant development for disseminating the results of biomedical research in our lifetime. "

Sir Paul Nurse, Cancer Research UK

Your research papers will be:

- available free of charge to the entire biomedical community

- peer reviewed and published immediately upon acceptance

- cited in PubMed and archived on PubMed Central

- yours - you keep the copyright
BioMedcentral 